\title{
Drivers of summer oxygen depletion in the central North Sea
}

\author{
Bastien Y. Queste ${ }^{1,2}$, Liam Fernand ${ }^{2}$, Timothy D. Jickells ${ }^{1}$, Karen J. Heywood ${ }^{1}$, and Andrew J. Hind ${ }^{1}$ \\ ${ }^{1}$ Centre for Ocean and Atmospheric Sciences (COAS), School of Environmental Sciences, University of \\ East Anglia, NR4 7TJ, Norwich, UK \\ ${ }^{2}$ Centre for Environment, Fisheries \& Aquaculture Science (CEFAS), Pakefield Road, NR33 0HT, Lowestoft, UK
}

Correspondence to: Bastien Y. Queste (b.queste@uea.ac.uk)

Received: 21 April 2015 - Published in Biogeosciences Discuss.: 12 June 2015

Revised: 3 February 2016 - Accepted: 9 February 2016 - Published: 29 February 2016

\begin{abstract}
In stratified shelf seas, oxygen depletion beneath the thermocline is a result of a greater rate of biological oxygen demand than the rate of supply of oxygenated water. Suitably equipped gliders are uniquely placed to observe both the supply through the thermocline and the consumption of oxygen in the bottom layers. A Seaglider was deployed in the shallow $(\approx 100 \mathrm{~m})$ stratified North Sea in a region of known low oxygen during August 2011 to investigate the processes regulating supply and consumption of dissolved oxygen below the pycnocline. The first deployment of such a device in this area, it provided extremely high-resolution observations, 316 profiles (every $16 \mathrm{~min}$, vertical resolution of $1 \mathrm{~m}$ ) of conductivity, temperature, and depth (CTD), dissolved oxygen concentrations, backscatter, and fluorescence during a 3-day deployment.

The high temporal resolution observations revealed occasional small-scale events $(<200 \mathrm{~m}$ or $6 \mathrm{~h})$ that supply oxygenated water to the bottom layer at a rate of $2 \pm 1 \mu \mathrm{mol} \mathrm{dm}{ }^{-3}$ day $^{-1}$. Benthic and pelagic oxygen sinks, quantified through glider observations and past studies, indicate more gradual background consumption rates of $2.5 \pm 1 \mu \mathrm{mol} \mathrm{dm}{ }^{-3} \mathrm{day}^{-1}$. This budget revealed that the balance of oxygen supply and demand is in agreement with previous studies of the North Sea. However, the glider data show a net oxygen consumption rate of $2.8 \pm 0.3 \mu \mathrm{mol} \mathrm{dm}{ }^{-3} \mathrm{day}^{-1}$, indicating a localized or shortlived $(<200 \mathrm{~m}$ or $6 \mathrm{~h})$ increase in oxygen consumption rates. This high rate of oxygen consumption is indicative of an unidentified oxygen sink. We propose that this elevated oxygen consumption is linked to localized depocentres and rapid remineralization of resuspended organic matter.

The glider proved to be an excellent tool for monitoring shelf sea processes despite challenges to glider flight posed
\end{abstract}

by high tidal velocities, shallow bathymetry, and very strong density gradients. The direct observation of these processes allows more up to date rates to be used in the development of ecosystem models.

\section{Introduction}

Mooring observations from 2007 and 2008 (Greenwood et al., 2010), historical data and a hydrographic survey of the North Sea in August 2010 (Queste et al., 2013) revealed repeated incidents of seasonal oxygen depletion in offshore waters of the central North Sea. In August 2011, a Seaglider was deployed in the region with the lowest recorded bottom mixed layer (BML) oxygen saturation from the 2010 survey to further investigate the mechanisms causing this seasonal oxygen depletion.

The North Sea is a relatively shallow (15-200 m) shelf sea situated between the islands of Great Britain, Orkney, and Shetland and northwestern continental Europe. It gradually deepens from south to north with the exception of the shallow Dogger Bank (Fig. 1). Dogger Bank effectively separates the North Sea into two regions of different physical, chemical, and biological properties (Otto et al., 1990; Lenhart et al., 1997). Water properties in the northern half of the North Sea are largely dominated by North Atlantic inflow. For their study of carbon dynamics, Thomas et al. (2005) determine the waters of the North Sea to be $90 \%$ sourced from the North Atlantic $\left(9000 \mathrm{~km}^{3} \mathrm{yr}^{-1}\right.$ via the Pentland Firth and Fair Isle, $42000 \mathrm{~km}^{3} \mathrm{yr}^{-1}$ via the Shetlands), $8 \%$ from the English Channel $\left(4900 \mathrm{~km}^{3} \mathrm{yr}^{-1}\right)$, and $2 \%$ from a combination of Baltic $\left(500 \mathrm{~km}^{3} \mathrm{yr}^{-1}\right)$ and riverine flow $\left(200 \mathrm{~km}^{3} \mathrm{yr}^{-1}\right)$. Water entering the North Sea from the north- 


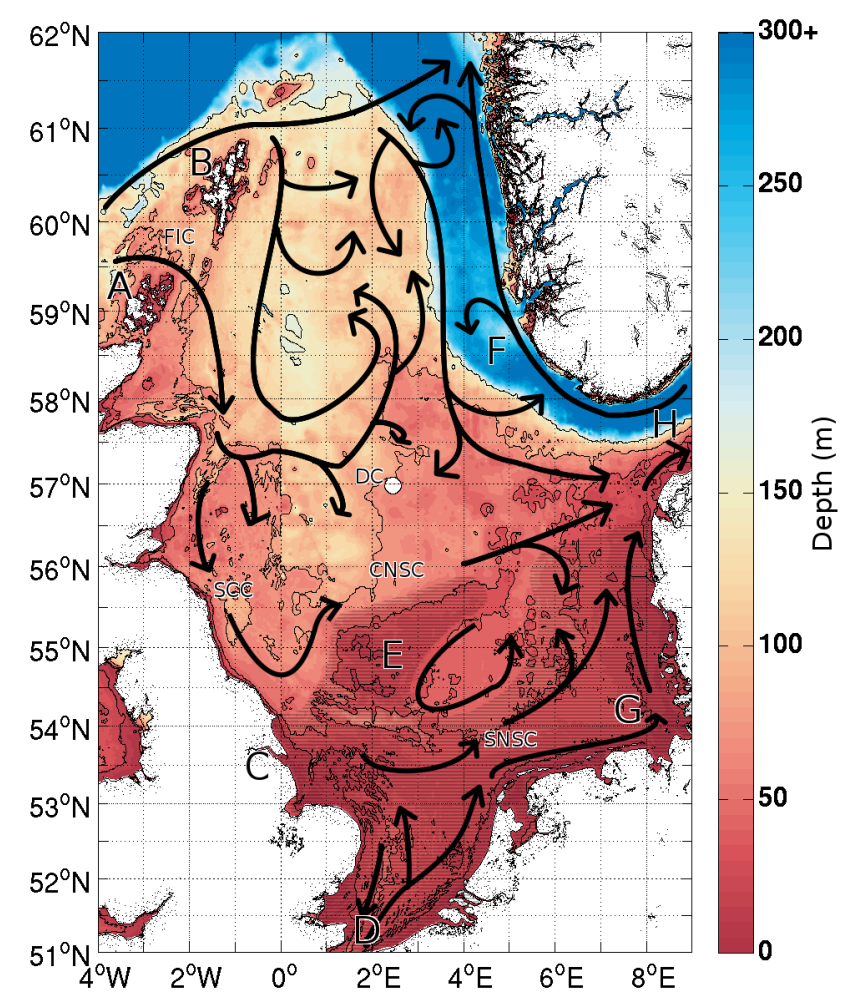

Figure 1. Bathymetry of the study area in metres (GEBCO, 2010). Depth contours have been added for the $20,40,80$, and $160 \mathrm{~m}$ isobaths. The region where the glider was deployed is indicated by the large white dot at approximately $57^{\circ} \mathrm{N}, 2^{\circ} 30^{\prime} \mathrm{E}$. Major landmarks are indicated as follows: $\mathrm{A}$ and $\mathrm{B}-$ Shetland and Orkney isles; C Humber estuary; D - the Channel; E - Dogger Bank; F - Norwegian Trench; G - German Bight; H - Skagerrak. The general circulation of the North Sea (adapted from Turrell et al., 1992 and Hill et al., 2008) is overlaid as arrows for FIC (Fair Isle Current), DC (Dooley Current), SCC (Scottish Coastal Current), CNSC (Central North Sea Current), and SNSC (Southern North Sea Current). Hatch marks cover areas not subject to thermal stratification in summer.

ern boundary generally circulates anticlockwise, following the Scottish coast southward before turning east and crossing the North Sea north of Dogger Bank (Brown et al., 1999; Turrell et al., 1992; Hill et al., 2008). The strength of this anticlockwise circulation is strongly correlated with the North Atlantic Oscillation Index (NAOI); positive NAOI is associated with strong anticlockwise circulation, while negative NAOI is associated with greatly reduced anticlockwise circulation in the northern North Sea (Lenhart et al., 1995, 2004; Rodwell et al., 1999). The northern half of the North Sea is seasonally stratified through surface heating. This stratification breaks down completely in winter (Ducrotoy et al., 2000; Sharples et al., 2006; Greenwood et al., 2010). Despite representing only $2 \%$ of the inflow, Baltic waters can play a disproportionate role in defining the biochemical properties of the central North Sea as under specific conditions of circulation or surface wind stress, the fresh water run-off issu- ing from the Baltic, Kattegat, and Skagerrak can be advected into the central region (Otto et al., 1990). This not only affects stratification by increasing the salinity difference between surface mixed layer (SML) and BML but also provides supplementary nutrients to the SML.

The August 2010 North Sea survey (Queste et al., 2013) recorded bottom waters with oxygen saturations below $70 \%$ in two regions; north of Dogger Bank (ND) and the Oyster Grounds (OG) (Fig. 2) exhibited dissolved oxygen saturations of circa $65 \%\left(200 \mu \mathrm{mol} \mathrm{dm}^{-3}\right)$ and $68 \%$ $\left(180 \mu \mathrm{mol} \mathrm{dm}{ }^{-3}\right)$ respectively. Historical data originating from the International Council for the Exploration of the Sea (ICES) database (Queste et al., 2013) revealed a similar distribution of low dissolved oxygen (DO) in the BML during summer in the ND and OG regions. The historical data also showed a sharp decline in summer oxygen saturations at these two sites since 1990. Queste et al. (2013) suggest that the same mechanisms likely lead to the depletion of oxygen at both the OG and ND sites. These mechanisms are thermal stratification preventing vertical resupply of oxygen; reduced advection slow replenishment of local BML oxygen and continuous remineralization of organic matter in the BML leads to gradual decline in oxygen concentrations. At both sites, it is thought that the replenishment of oxygenated waters through advective processes is limited by local topography. ND is situated away from the fronts associated with the north side of the shallow Dogger Bank; it is characterized by variable, weak wind-driven currents (Otto et al., 1990). This slow circulation limits the horizontal supply of DO while weak tidal currents also promote settling of organic matter. Weak winds and strong surface heat fluxes promote stratification and keep the BML isolated from air-sea exchange. There is also a weak inflow of oxygenated waters as tides and topography lead to the formation of bottom fronts to the south and east of the OG site (Van Raaphorst et al., 1998; Weston et al., 2008). Organic matter produced at the pycnocline along the deep chlorophyll maximum (DCM), particularly at ND, is exported directly into the BML (Thomas et al., 2004; Weston et al., 2008; Fernand et al., 2013). This organic matter, when remineralized, leads to the consumption of DO in the BML. At both the OG and ND sites, it has been suggested that mixing events may cause resuspension of bottom sediment. Transfer of this organically rich sediment into an oxic water column could cause rapid increases in pelagic DO consumption (Van Raaphorst et al., 1998; Greenwood et al., 2010).

The intensity and duration of oxygen depletion depend on the relative magnitudes of oxygen consumption and oxygen supply. These processes can be both spatially and temporally variable. This study took place in 2011 , when we observed a different spatial pattern than in 2010. The oxygen-depleted area experienced an overall northward shift but with similar intensities of oxygen depletion (Fig. 2). To accurately predict potential seasonal oxygen consumption under future climate scenarios, it is necessary to identify the relative magnitude of 

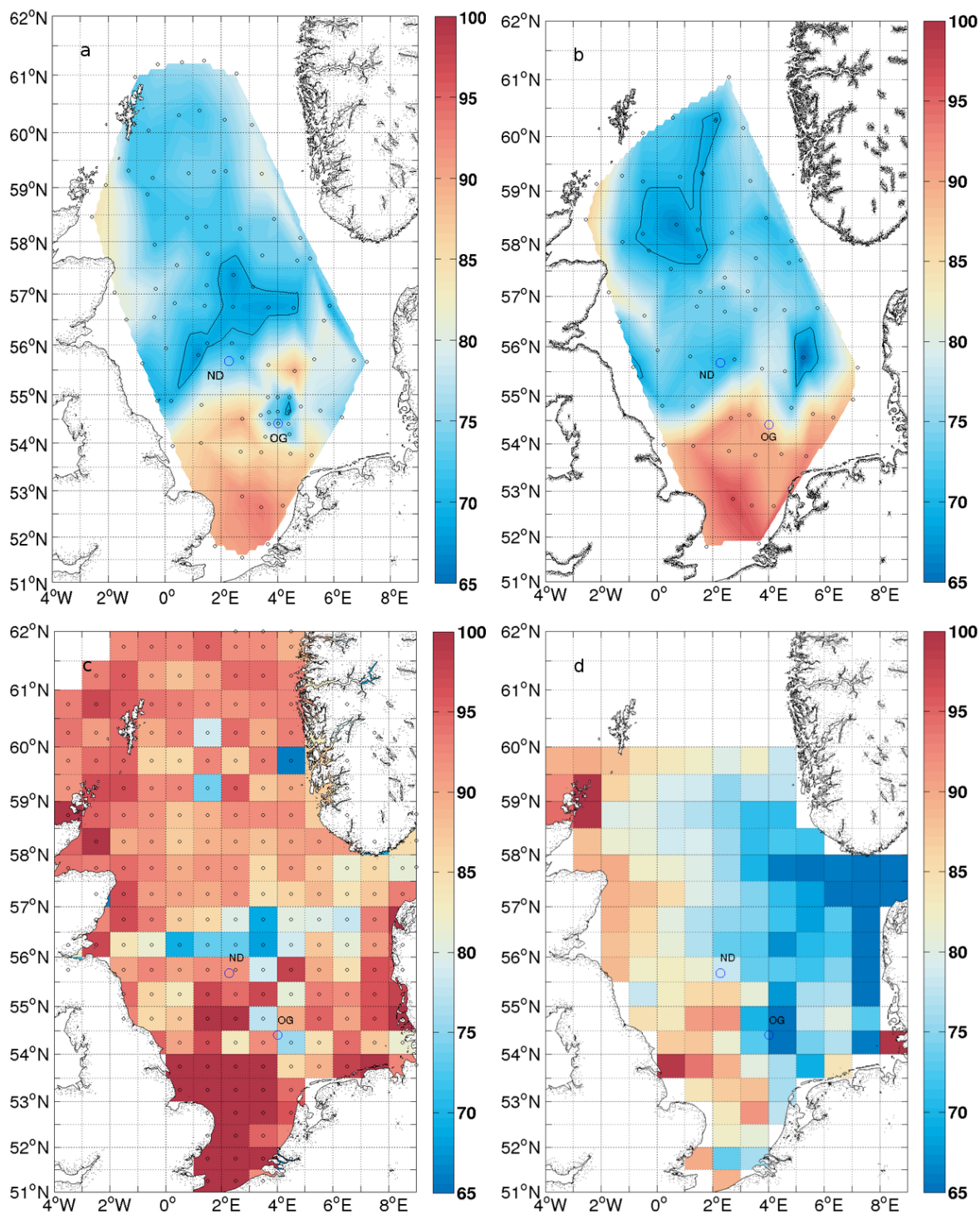

Figure 2. BML oxygen saturation (\%) and with the $70 \%$ saturation contour during the August 2010 (a) and August 2011 surveys (b), mean summer bottom oxygen saturation values (\%) from 1900 to 2010 from the ICES database (c), and mean summer bottom oxygen saturation values (\%) from 1958 to 2008 from the General Estuarine Transport Model-European Regional Seas Ecosystem Model (GETM-ERSEM) output using European Centre for Medium-Range Weather Forecasts (ECMWF) European Reanalysis (ERA)-interim data (d).

sources of organic matter that lead to the consumption of DO in the BML and the amount of DO supply through the pycnocline on a finer scale. There is growing interest in the issue of low oxygen in coastal waters around the world (Diaz and Rosenberg, 2008), and further research is required to effectively manage the impact of hypoxia in coastal waters. This study aims to improve our understanding of the key shortterm mixing processes that regulate oxygen supply at high temporal frequency by quantifying through Seaglider observations the major inputs and sinks of dissolved oxygen.

\section{Seaglider observations}

A Seaglider from the University of East Anglia, SG510, was deployed at $56^{\circ} 41.96^{\prime} \mathrm{N}, 2^{\circ} 26.37^{\prime} \mathrm{E}$ on the 19 August 2011 (Fig. 1) at a water depth of $\approx 75 \mathrm{~m}$. Seagliders are buoyancydriven autonomous underwater vehicles that move through the water in a sawtooth pattern between the surface and the seabed (or $1000 \mathrm{~m}$ in deeper water; Eriksen et al., 2001). Typically, the glider recorded data between $2 \mathrm{~m}$ from the surface and $7 \mathrm{~m}$ off the seabed; sample points beyond this range were discarded because of poor flow conditions due to the glider turning around. Seagliders sample every $5 \mathrm{~s}$ using an onboard sensor suite composed of a Seabird unpumped conduc- 

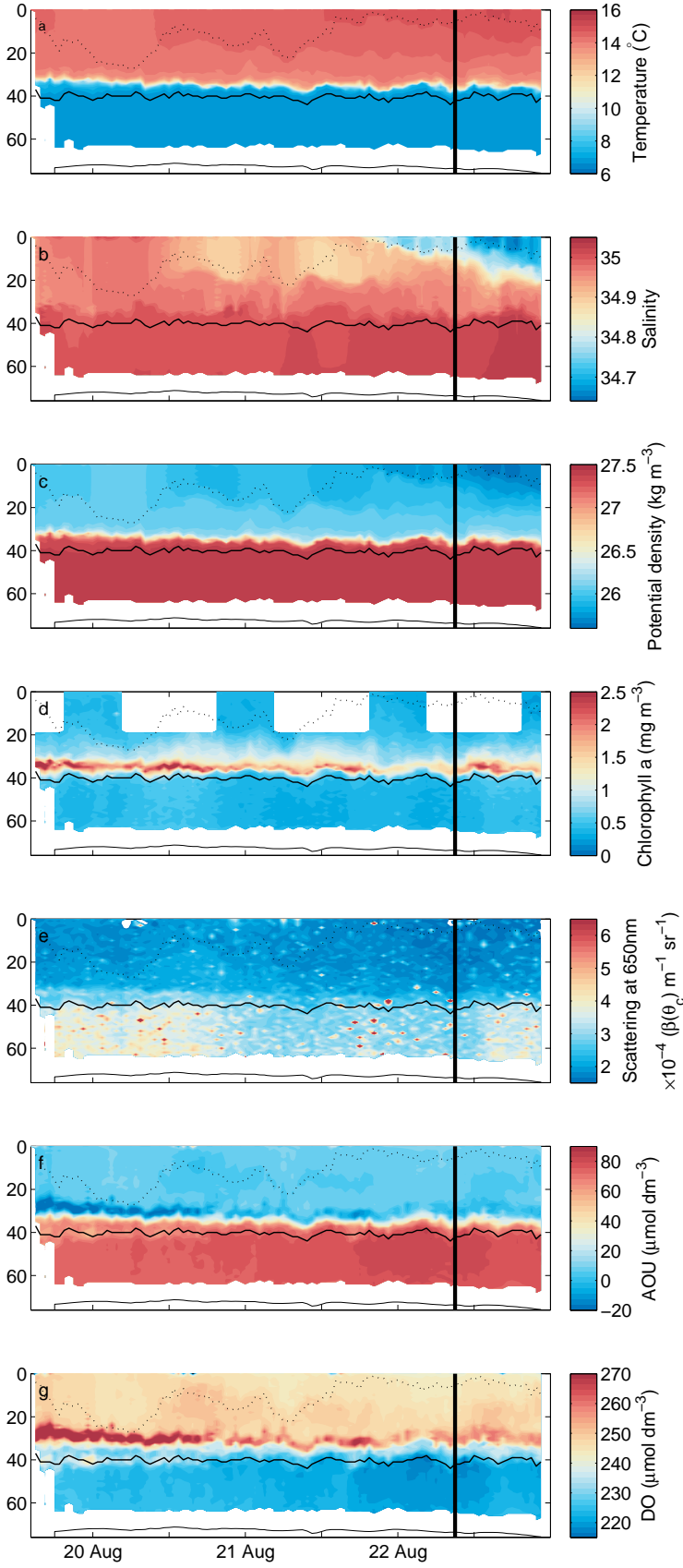

Figure 3. Seaglider section of temperature $\left(\mathbf{a} ;{ }^{\circ} \mathrm{C}\right)$, salinity (b; PSU), potential density $\left(\mathbf{c} ; \mathrm{kg} \mathrm{m}^{-3}\right)$, chlorophyll $a$ concentration $\left(\mathbf{d} ; \mathrm{mg} \mathrm{m}^{-3}\right)$, optical scattering as a volume scattering function at $650 \mathrm{~nm}\left(\mathbf{e} ; \times 10^{-4} \beta\left(\theta_{c}\right) \mathrm{m}^{-1} \mathrm{sr}^{-1}\right)$, apparent oxygen utilization $\left(\mathbf{f} ; \mu \mathrm{mol} \mathrm{dm}{ }^{-3}\right)$ and oxygen concentration $\left(\mathbf{g} ; \mu \mathrm{mol} \mathrm{dm}{ }^{-3}\right)$ sampled along the transect. Bathymetry as detected by the onboard altimeter is indicated along the bottom. Daytime chlorophyll $a$ values showing signs of quenching are blanked. The vertical black line indicates the transition to a different water mass; data after this vertical black line are excluded from the oxygen calculations. The solid black contour indicates the $7^{\circ} \mathrm{C}$ isotherm. The dotted black contour indicates the mixed layer depth $\left(\sigma>0.01 \mathrm{~kg} \mathrm{~m}^{-3}\right)$. tivity and temperature sensor, a Wetlabs Triplet EcoPuck, and an Aanderaa 4330F optode. SG510 sampled along a $32 \mathrm{~km}$ northward transect during a 3-day period (158 dives, 316 vertical profiles) providing a full depth cast every $7.8 \pm 0.8 \mathrm{~min}$.

Temperature and salinity were calibrated against an in situ ship-based profile at launch; dissolved oxygen and chlorophyll $a$ were calculated using recent manufacturer calibrations. Chlorophyll $a$ concentrations obtained from the glider were validated against data obtained by an ESM2 logger deployed during the glider launch; the ESM2 logger calibration is regularly compared to in situ high-performance liquid chromatography (HPLC) and fluorometry samples. Data were corrected for sensor lag and time offsets; further details are provided by Queste (2014). Due to the sharp temperature gradient, significant hysteresis remained in temperaturedependent variables (salinity, density, oxygen) relating to the thermal inertia of the different sensors. As the region contained two fairly uniform mixed layers, composite profiles were created using upcasts between the seabed and the thermocline and downcasts between the surface and the thermocline. This eliminated the bias due to the thermal inertia of the conductivity cell and oxygen optode. The composite profiles were then gridded over time and pressure by taking the mean value in each $45 \mathrm{~min}$ by $1 \mathrm{dbar}$ grid square to provide regularly spaced data. Chlorophyll $a$ measurements were impacted by daytime quenching. Data prone to quenching were removed from the analysis and show up as blank in Fig. 3. Daytime profiles were omitted when calculating the mean chlorophyll $a$ profile in Fig. 4.

Figures 3 and 4 present the data collected by SG510 during its 3-day mission. The glider is able to resolve significant and systematic changes in all the measured parameters on this timescale. The glider observed strong stratification $\left(>1.5 \mathrm{~kg} \mathrm{~m}^{-3}\right.$ ) throughout the 3 days (Figs. 3 and 4), separating two well-mixed layers: the SML and the BML. The SML showed warming throughout the survey with a temperature difference of $1{ }^{\circ} \mathrm{C}$ between beginning and end and a decrease in surface salinity $(0.35)$ as the glider entered a region of fresher surface water on the third day; this fresher surface water likely originated from Baltic outflow (Fig. 5). The BML exhibits a small and opposite pattern, with temperatures decreasing by less than $0.1{ }^{\circ} \mathrm{C}$ on the third day and salinity increasing by 0.15 . As the glider crossed a surface feature and observed a significant change in temperature and salinity at the end of the survey, data from the last $15 \mathrm{~h}$ of the survey are excluded when calculating rates of oxygen depletion.

The strong pycnocline maintains a subsurface phytoplankton community, as evidenced by the DCM (Figs. 3d and 4d). Variations in chlorophyll $a$ concentration (as estimated by fluorescence intensity) occur throughout the survey; peaks in DCM fluorescence coincide with decreases at the surface. The surface variation of chlorophyll $a$ fluorescence is likely caused by quenching rather than by a loss of biomass or pigment as it occurs daily at noon. Fluctuations in chlorophyll $a$ 

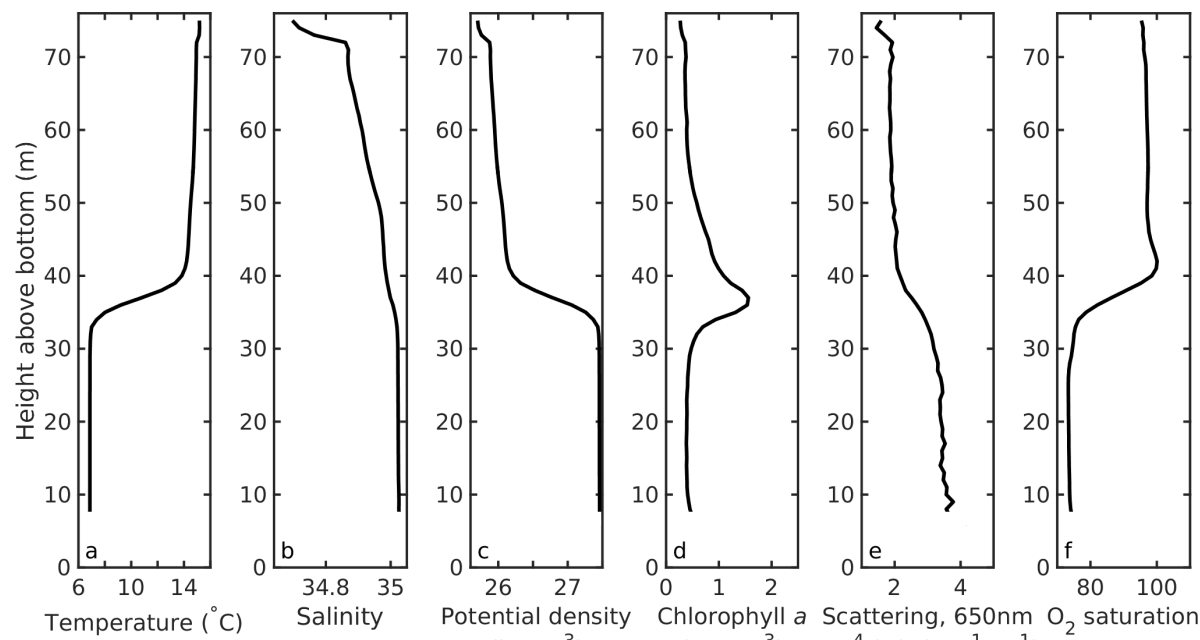

$$
\left(\mathrm{kg} \mathrm{m}^{-3}\right)
$$$$
\left(\mathrm{mg} \mathrm{m}^{-3}\right) \quad 10^{-4}\left(\beta\left(\theta_{\mathrm{c}}\right) \mathrm{m}^{-1} \mathrm{sr}^{-1}\right)
$$

(\%)

Figure 4. Mean profiles as observed by the Seaglider of temperature $\left(\mathbf{a} ;{ }^{\circ} \mathrm{C}\right)$, salinity $(\mathbf{b} ; \mathrm{PSU})$, potential density $\left(\mathbf{c} ; \mathrm{kg} \mathrm{m}^{-3}\right)$, chlorophyll $a$ concentration $\left(\mathbf{d} ; \mathrm{mg} \mathrm{m}^{-3}\right)$, optical scattering as a volume scattering function at $650 \mathrm{~nm}\left(\mathbf{e} ; \times 10^{-4} \beta\left(\theta_{c}\right) \mathrm{m}^{-1} \mathrm{sr}^{-1}\right)$, and oxygen saturation (f; \%) as height above the seabed. Daytime profiles were omitted for chlorophyll $a$.

concentration are visible throughout the BML but do not coincide with the diurnal signal described above. These BML fluctuations likely relate to sinking organic matter and are also observed by the optical backscatter sensor; pulses in optical backscatter at $650 \mathrm{~nm}$ can be seen in the BML repeatedly throughout the 3-day survey (Fig. 3d and e).

Apparent oxygen utilization (AOU; defined as the difference between the solubility of dissolved oxygen and observed oxygen concentration; Fig. 3f) shows a pattern typical of oxygen change within the central stratified North Sea (Queste et al., 2013). The SML is homogenously saturated. At the pycnocline, supersaturation (negative AOU) is visible and correlated with elevated chlorophyll $a$ concentration (Fig. 4f); this supersaturation is evidence of strong primary production occurring at the DCM (Weston et al., 2005). The BML exhibits increasing AOU throughout the survey; this oxygen depletion is caused by the remineralization of organic matter within the BML and isolation from air-sea exchange by the strong density gradient.

\section{Dissolved oxygen budget}

To constrain the balance of DO consumption and supply, we quantify the various sources and sinks of DO and compare these with the observed change in DO over the survey period. Pena et al. (2010) review the processes that affect DO. These are represented conceptually in Fig. 6. Advective and dispersive transport (both horizontal and vertical), air-sea exchange, and biological production and consumption are the three dominant processes.

In the context of a strongly stratified two-layer system, airsea exchange does not affect the BML and can be neglected. In this region and on short timescales (3 days), horizontal ad- vective and diffusive processes can be neglected for the BML due to the homogeneity of the BML across the central North Sea (Queste et al., 2013). Therefore, for the BML in this region, the vertical cross-thermocline transport and biological processes dominate (Greenwood et al., 2010).

As evidenced by the chlorophyll $a$ and supersaturation signatures (Fig. 3), the majority of the production occurs within the DCM and SML. Consequently, the dominant biological processes within the BML are (i) benthic oxygen demand and (ii) the remineralization of organic matter which may derive from (a) sinking from the DCM and (b) organic matter still in suspension issuing from the spring bloom. Net oxygen change is therefore determined by the balance of oxygen supply from cross-thermocline mixing and remineralization of benthic organic matter and matter sinking from the DCM.

\section{Observed change in dissolved oxygen in the BML}

Figure 7 illustrates AOU at different depths throughout the BML. AOU is shown at depths beginning several metres below the pycnocline to account for tidal vertical displacement. As we are not measuring mean BML temperature value, vertical displacement of the thermocline does not impact assessment of vertical temperature gradients. As we are looking at a gradient rather than absolute values, displacement of the BML simply moves this gradient up and down but does not affect the slope or extent. There is a clear trend of uniformly increasing AOU over time, indicating oxygen depletion, throughout the entire BML. A linear regression of mean AOU throughout the BML indicates a rate of $2.8 \mu \mathrm{mol} \mathrm{dm}{ }^{-3} \mathrm{day}^{-1}$ of DO consumption with a standard error of the regression of 0.3. Three sharp decreases in AOU are indicated by the vertical dotted line. These relate to vertical 

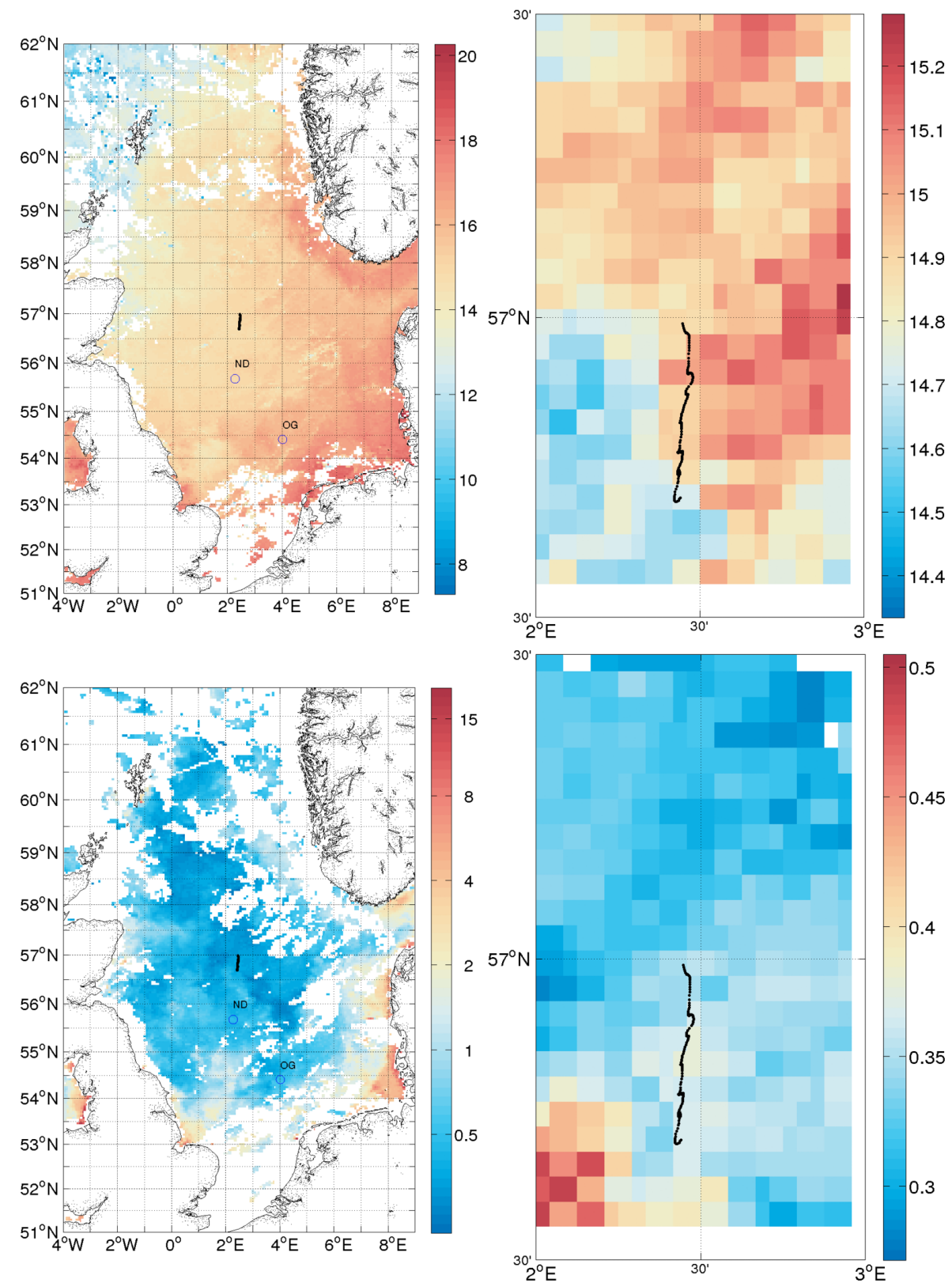

Figure 5. Three-day composite of MODIS Aqua daytime sea surface temperature at $11 \mu \mathrm{m}\left({ }^{\circ} \mathrm{C}\right.$, $\mathbf{a}$ and $\left.\mathbf{b}\right)$ and chlorophyll $a$ concentration $\left(\mathrm{mg} \mathrm{m}^{-3}\right.$, (c) and d) across the entire North Sea (left) and around the Seaglider deployment area (right) from the 20 to 22 August 2011 . The colour scale for the North Sea map of chlorophyll $a$ is logarithmic to highlight chlorophyll $a$ distribution in the central North Sea where concentrations are low. Northward Seaglider track is indicated by the black line.

mixing events identified in Fig. 8 and will be discussed in the following section.

An oxygen consumption rate of $2.8 \pm 0.3 \mu \mathrm{mol} \mathrm{dm}^{-3} \mathrm{day}^{-1}$ is very large; to reach the observed AOU of $76 \mu \mathrm{mol} \mathrm{dm}{ }^{-3}$ from saturation would require no more than 1 month. Continuous consumption at this rate over the entire summer would very rapidly lead to severe hypoxia. However, in this region, stratification begins near the end of April (Sharples et al., 2006), more than 3 months before the survey occurred. Greenwood et al. (2010) observed a lower rate of DO consumption, with an average of $0.4 \mu \mathrm{mol} \mathrm{dm}{ }^{-3}$ day $^{-1}$ across the entire summer season at ND. It is therefore likely that strong reoxygenation events occurred or the mean rate of oxygen consumption was lower during the first half of the stratified season and that the glider observed a temporal local maximum in consumption rates. Despite this, these observations are representative of specific conditions which occur in the central North Sea and 


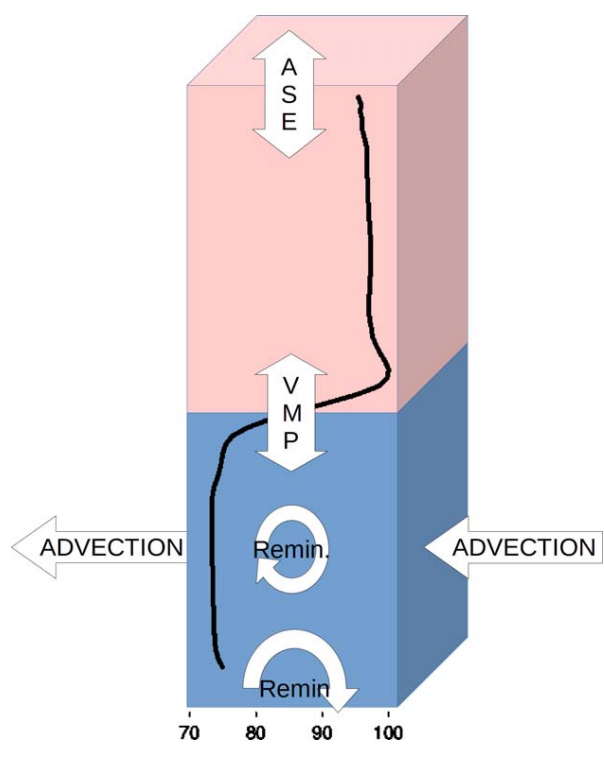

Figure 6. A conceptual representation of the processes affecting oxygen supply and consumption to the bottom mixed layer during the glider survey. The water column is separated into two layers: the SML and BML (red and blue). The observed mean oxygen saturation profile (from Fig. 4) is overlaid on the water column to illustrate the position of the oxycline and deep chlorophyll maximum (indicated by the mid-water peak). ASE: air-sea exchanges; VMP: vertical mixing processes; Remin.: remineralization of organic matter.

which are likely a recurring maximum of depletion rates within the summer season. It therefore follows that consumption of organic matter in the sediment and pelagically (from the DCM and spring bloom) surpasses the supply of oxygenated water from cross-thermocline exchange by $2.8 \pm 0.3 \mu \mathrm{mol} \mathrm{dm}^{-3}$ day $^{-1}$.

The following sections aim to quantify both supply of oxygen and remineralization rate terms using previous studies and the glider observations in order to close the budget.

\section{Supply of oxygenated water}

To observe the supply of DO to the BML through time, ideally the glider would act as a Lagrangian platform moving with the water. This requires no horizontal displacement of the glider relative to the water. Based on the August 2010 hydrographic survey of Queste et al. (2013), it was expected that horizontal gradients would be minimal in this region and therefore that any horizontal displacement would have a negligible impact on observed water mass properties. However, August 2011 was different to August 2010 in terms of surface circulation and hydrographic characteristics. Sea surface temperature and chlorophyll $a$ concentration across the North Sea during the deployment derived from MODerate Resolution Imaging Spectrometer (MODIS) Aqua data (Fig. 5) reveal significant horizontal variability near the Seaglider transect in surface waters. This surface variability is clearly shown in Fig. 3b where the Seaglider observed a freshening of 0.3 of the SML at the end of the survey. This change was not reflected in the BML, where the glider observed a weak but opposing trend. In the BML, the Seaglider observed a $0.1{ }^{\circ} \mathrm{C}$ cooling and 0.03 salinification (together equivalent to a densification of $0.035 \mathrm{~kg} \mathrm{~m}^{-3}$ ), likely due to increasing Atlantic water influence.

Although both 2010 and 2011 show an overall similar spatial pattern with depleted oxygen in the northern half; areas of lowest oxygen saturation are located in different regions (Fig. 2). Given the potentially very high consumption rates, these patterns of oxygen saturation are mainly a snapshot set of observations of late summer and may not be representative of the entire season or the previous month. This illustrates the interannual variability and importance of horizontal transport processes on broad scales in the North Sea, and also potentially in other shelf seas, linked to other dominating climate modes. Horizontal transport processes likely affect seasonal oxygen depletion by influencing BML and SML temperatures, thereby affecting stratification while also providing nutrients to sustain productivity and potentially supplying labile organic matter to the BML.

On timescales similar to those in this survey, it is likely that advective processes play a limited role in regulating seasonal oxygen depletion; instead, vertical mixing is assumed to be the largest potential source of oxygen input into the BML. Seaglider observations reveal a highly stratified water column with a strong pycnocline spanning approximately $8 \mathrm{~m}(\sim 30-38 \mathrm{~m})$ with a density difference of $1.5-2 \mathrm{~kg} \mathrm{~m}^{-3}$ (Fig. 3c). Evidence of mixing can be found in changing properties of the BML as observed by the glider. Here, temperature is used as a tracer to assess mixing across the pycnocline on short timescales through the large temperature difference between the SML and BML (Fig. 8). Temperature data from below the thermocline are used to derive the vertical temperature gradient in the BML (Fig. 8, black vertical lines). A small value indicates a homogenous BML while a large value indicates a strong vertical gradient in the BML. Figure 8 shows changes in vertical temperature gradients on the order of a few hours (or hundreds of metres) horizontally. The BML temperature gradient increases simultaneously to mean BML temperature. This indicates warming of BML water by mixing across the thermocline and injection of warm SML water into the cooler BML.

Referring back to Fig. 7, we observe similar fluctuations in AOU. The three principal mixing events, illustrated by the grey vertical lines, correspond to sudden decreases in AOU, indicating sudden and rapid reoxygenation of the BML. After these reoxygenation events, net oxygen consumption rates increase within a few hours. The three events over the 3 days show increases in BML DO (decreases in AOU) of approximately 1 to $3 \mu \mathrm{mol} \mathrm{dm}{ }^{-3}$ per event $\left(2 \pm 1 \mu \mathrm{mol} \mathrm{dm}{ }^{-3}\right.$ day $\left.^{-1}\right)$.

Figure 9 shows wind velocity and tidal currents along with bathymetry at the glider's position. There is no obvious cor- 


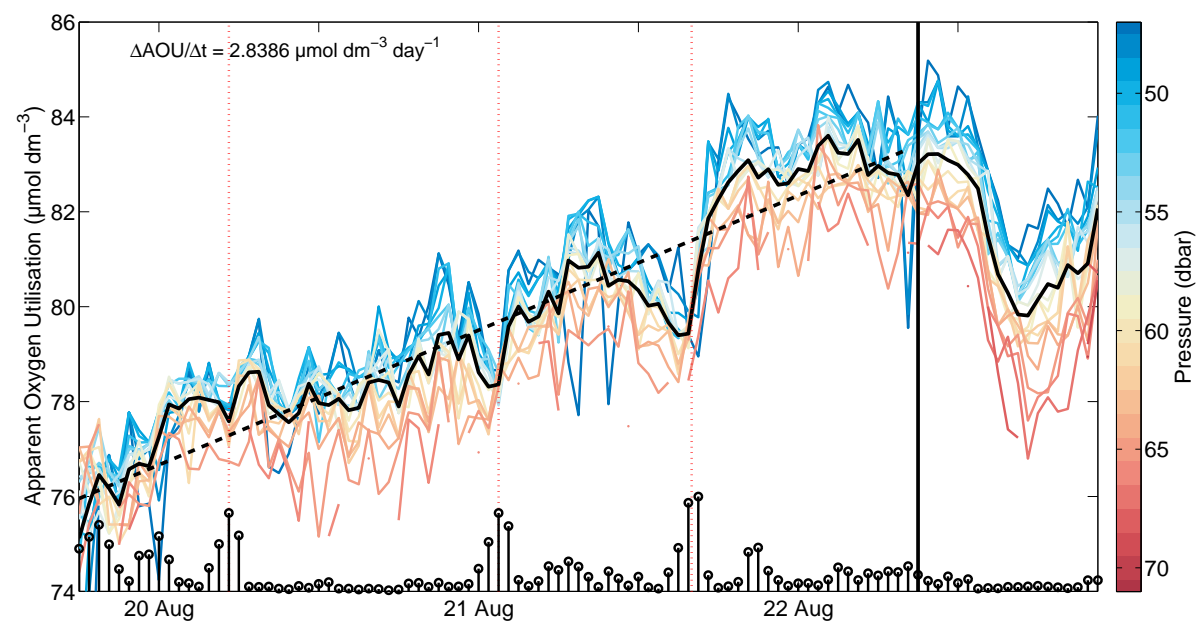

Figure 7. Seaglider apparent oxygen utilization $\left(\mu \mathrm{mol} \mathrm{dm}^{-3}\right)$ along isobars at 1 dbar intervals from 45 to 71 dbar, coloured by pressure. Black vertical lines indicate the maximum difference in temperature at each time step as shown in Fig. 8. Binned data from the BML (45 dbar and below) are plotted against time and coloured by pressure to highlight any vertical gradients. The dotted vertical lines indicate when vertical mixing events were evident. The vertical black line indicates the transition to a different water mass.

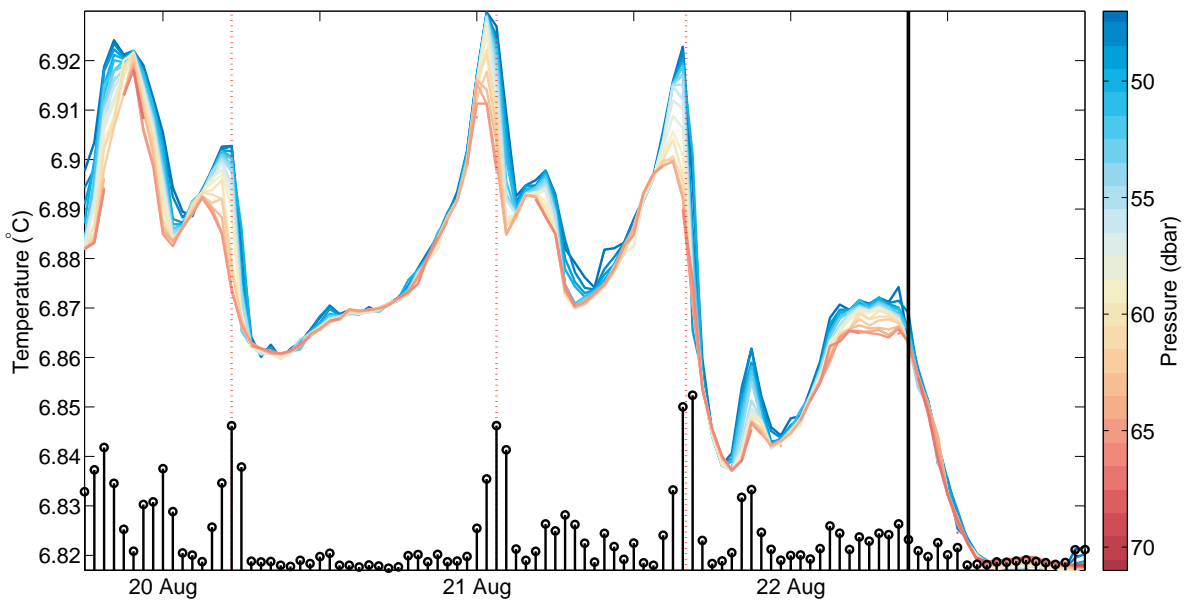

Figure 8. Seaglider temperature $\left({ }^{\circ} \mathrm{C}\right)$ along isobars at $1 \mathrm{dbar}$ intervals from 45 to $71 \mathrm{dbar}$, coloured by pressure. Vertical black stems indicate the difference between minimum and maximum values at each time step. This illustrates changes in vertical gradients; a small value indicates a homogenous BML, while a large value indicates a strong vertical gradient in the BML. We can clearly see events where the temperature gradient increases in the BML, showing injection of warmer surface water across the thermocline.

relation between the mixing events identified in Fig. 8 and currents. The majority of mixing events tends to occur during periods of peak wind velocities, but the duration of mixing events does not seem to match the timescale of wind velocity changes; furthermore, two mixing events occur in periods of low wind velocities. Mixing events do not seem to correlate with bathymetry in the region either (Fig. 9).

These mixing events are short-term (a few hours or a couple of kilometres) processes that the Seaglider is able to reveal through its very high-resolution observations. Since wind events do not seem to be responsible, these events may be linked to a variety of physical processes occurring in the region. Van Haren et al. (1999) highlighted the importance of internal waves as a potential source of mixing around the Dogger Bank. Another possibility is the generation of shear spikes as described by Burchard and Rippeth (2009) due to the interaction of wind and tides, explaining the lack of correlation with either one in particular.

Regardless of the cause, we observe short-lived or very localized occasional oxygen resupply events leading to an approximate oxygen supply of $2 \pm 1 \mu \mathrm{mol} \mathrm{dm}{ }^{-3} \mathrm{day}^{-1}$. Relating this back to the overall oxygen budget, we observed a net oxygen consumption rate of $2.8 \pm 0.3 \mu \mathrm{mol} \mathrm{dm}^{-3} \mathrm{day}^{-1}$

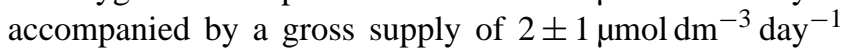
through vertical cross-thermocline mixing processes. 


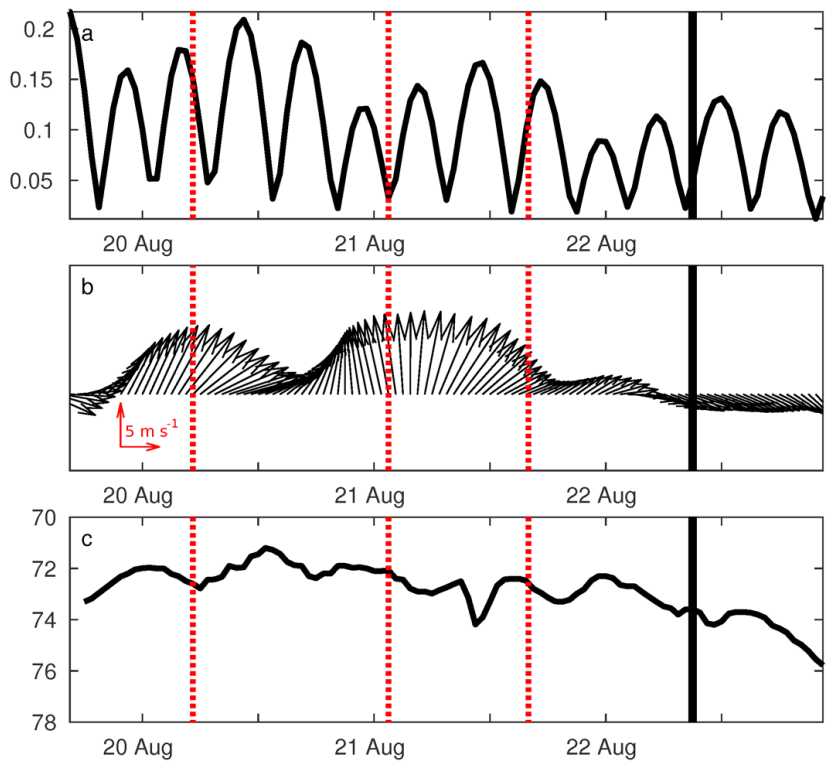

Figure 9. Tidal currents $\left(\mathrm{m} \mathrm{s}^{-1}, \mathbf{a}\right), 10 \mathrm{~m}$ wind speed with scale arrows representing $5 \mathrm{~m} \mathrm{~s}^{-1}$ (b), and depth $(\mathrm{m}, \mathbf{c})$ at the Seaglider's location during the survey. The dotted vertical lines indicate when vertical mixing events were evident. The vertical black line indicates the transition to a different water mass. Tidal data were obtained from the Tidal Model Driver (TMD) tide toolbox and OTIS (OSU (Oregon State University) Tidal Inversion Software) European Shelf Model (Egbert et al., 2010). Wind data was obtained from ECMWF ERA-Interim reanalysis data. Bathymetry was gathered by the Seaglider's on-board altimeter. The comparison was made by extracting data from the closest point in time and space to the glider's location from the ECMWF 6-hourly high-resolution data. Linear interpolation was used in time between the ECMWF data.

\section{Oxygen consumption}

\subsection{Benthic respiration}

We now assess the relative magnitude of the different oxygen sinks within the BML. As the North Sea is a shallow region, vertical transport of organic matter from the SML and BML to the benthic layer is fairly rapid. On the whole North Sea scale, Van Raaphorst et al. (1998) report that 17 to $45 \%$ of primary production is remineralized in the sediments, although the bulk of this occurs in the Skagerrak and Norwegian Trench area (50 to $70 \%$ ) due to transport processes. On a more local scale, tidal currents resuspend and transport this organic matter to temporary depocentres. This makes estimating benthic respiration across the North Sea difficult due to the consequent spatial heterogeneity. Van Raaphorst et al. (1998) report that particulate matter from the East Anglian plume and the southern North Sea may settle in the OG and the southern flank of the Dogger Bank.

Neubacher (2009) directly measured nutrient and oxygen dynamics at the benthic-pelagic interface at the ND site. DO uptake by the sediment was determined to be approximately $250 \mu \mathrm{mol} \mathrm{m}{ }^{-2} \mathrm{~h}^{-1}$, with variations linked to organic matter export to the benthic layer. Assuming a uniformly mixed BML with a height of $38 \mathrm{~m}$ (Fig. 3), this amounts to a decline in oxygen concentration of $1.6 \mu \mathrm{mol} \mathrm{dm}^{-3} \mathrm{day}^{-1}$ consumed throughout the BML from respiration in the sediment.

\subsection{Remineralization of DCM-originating organic matter}

Primary production estimates for the North Sea range from 40 to $300 \mathrm{~g} \mathrm{C} \mathrm{m}^{-2} \mathrm{yr}^{-1}$ depending on area and technique (modelling or empirical), with maxima in the central North Sea area (north of Dogger Bank; Weston et al., 2005). A transect by Weston et al. (2005) north of Dogger Bank showed whole-water-column-integrated primary production values of 167,370 , and $270 \mathrm{~g} \mathrm{C} \mathrm{m}^{-2} \mathrm{yr}^{-1}$ for areas classified as Dogger Bank, the front (located along the northern edge of Dogger Bank), and the stratified area (the ND site) respectively.

More recently, the importance of the DCM has been reviewed. The DCM contribution to total primary production for the stratified North Sea during the summer has been estimated at between 58 and $60 \%$ (Fernand et al., 2013; Weston et al., 2005). Values for new production range from 37 to $66 \%$ produced at the DCM for the whole water column (Fernand et al., 2013; Weston et al., 2005). As the DCM is sustained by intermittent, enhanced turbulent fluxes of nutrients from the BML (Sharples et al., 2001; Williams et al., $2013 \mathrm{~b}, \mathrm{a})$, it is necessarily located very near to the pycnocline. Consequently, any mixing also injects highly labile organic matter into the BML. Furthermore, sinking organic matter produced at the DCM is exported to the BML immediately; therefore, any remineralization of organic matter occurs in the BML. This means that nearly all export production from the DCM is consumed within the BML.

The Seaglider observed DCM chlorophyll $a$ concentrations of 2 to $3 \mathrm{mg} \mathrm{m}^{-3}$ in 2011 (Fig. 3). These values are similar to those found by Fernand et al. (2013) but lower than concentrations observed by Weston et al. (2005) (ca. 5$10 \mathrm{mg} \mathrm{m}^{-3}$ ). This is likely explained by the systematic variation in DCM chlorophyll $a$ concentrations across the North Sea. The site considered here is located further north than the site investigated in the Weston et al. (2005) study and is not subject to as much mixing from internal waves fuelling the DCM in the ND region (Ducrotoy et al., 2000; Weston et al., 2005). Chlorophyll $a$ concentrations at the DCM fluctuate on a near diurnal cycle (Fig. 3). This may be linked to either fluctuations in light availability or a diurnal change in wind velocities. Increased wind speed could lead to an increase in chlorophyll $a$ fluorescence a few hours later by encouraging nutrient supply to the DCM. Fluctuations in chlorophyll $a$ at the DCM (Fig. 3) are not due to quenching as periods of high DCM chlorophyll $a$ concentrations are present when surface chlorophyll $a$ fluorescence is affected by high light intensity. 
Instead, it is possible that these fluctuations in chlorophyll $a$ fluorescence at the DCM may be caused by increases in nutrient supply linked to stronger winds that occurred in the mornings (Fig. 9).

We now investigate the export of DCM organic matter to the BML. Figure 3d shows a similar pattern for BML chlorophyll $a$ concentration and DCM chlorophyll $a$ concentrations. We observe a delay between peaks in DCM chlorophyll and BML chlorophyll with BML chlorophyll $a$ concentrations peaking a few hours later. As we have already observed a delay between peaks in wind velocities and DCM chlorophyll $a$ concentrations, we can assume that wind-driven mixing is not responsible for injecting these large amounts of organic matter into the BML. Neither are these increases in BML chlorophyll $a$ correlated to tidal velocities or changes in BML salinity, thus ruling out the influence of horizontal transport processes or tidal mixing on export of DCM organic matter to the BML. It seems likely that the wind drives production at the DCM but export mechanisms are driven by biological processes.

The Seaglider data show pulses, or short-lived increases, in BML chlorophyll $a$ concentrations of $0.15 \mathrm{mg} \mathrm{m}^{-3}$ occurring on daily cycles. We assume these are events where DCM organic matter sinks to the BML. With an approximate BML height of $38 \mathrm{~m}$, these pulses equate to $5.7 \mathrm{mg} \mathrm{m}^{-2}$ day $^{-1}$ of chlorophyll $a$ export to the BML. Using a particulate organic carbon (POC) to chlorophyll $a$ ratio of $50: 1$ (Sathyendranath et al., 2009; Weston et al., 2004), this amounts to an export of approximately $0.285 \mathrm{~g} \mathrm{C} \mathrm{m}^{-2} \mathrm{day}^{-1}$ to the BML. If all this organic matter were to be remineralized within the BML, this would equate to $33.58 \mathrm{mmol} \mathrm{DO} \mathrm{m}^{-2} \mathrm{day}^{-1}$ or $0.9 \mu \mathrm{mol} \mathrm{dm}{ }^{-3} \mathrm{day}^{-1}$ (as per the Redfield ratio; Redfield, 1934). Although chlorophyll $a$ is not a direct proxy for POC due to the non-fluorescence of decayed organic matter and lysed cells, the $50: 1$ ratio was determined empirically and therefore also accounts for non-fluorescing organic matter. Based on the variability of chlorophyll $a$ within the DCM, the calibration of the glider sensor and the variability of the POC to chlorophyll $a$ ratio $(<25 \%)$, we estimate the error of our oxygen consumption estimate to be $\pm 1 \mu \mathrm{mol} \mathrm{dm}{ }^{-3}$ day $^{-1}$.

By summing the benthic $\left(1.6 \mu \mathrm{mol} \mathrm{dm}{ }^{-3} \mathrm{day}^{-1}\right)$ and pelagic $\left(0.9 \mu \mathrm{mol} \mathrm{dm}{ }^{-3} \mathrm{day}^{-1}\right)$ oxygen sinks within the budget, we obtain a gross oxygen remineralization rate of $2.5 \pm 1 \mu \mathrm{mol} \mathrm{dm}{ }^{-3} \mathrm{day}^{-1}$. Linking these observations back to the initial budget, we observed a net oxygen consumption rate of $2.8 \pm 0.3 \mu \mathrm{mol} \mathrm{dm}{ }^{-3}$ day $^{-1}$, a gross supply of $2 \pm 1 \mu \mathrm{mol} \mathrm{dm}{ }^{-3} \mathrm{day}^{-1}$, and a gross remineralization rate of $2.5 \pm 1 \mu \mathrm{mol} \mathrm{dm}{ }^{-3} \mathrm{day}^{-1}$.

\section{Balance of consumption and supply}

Oxygen consumption arising in the water column from recently exported matter $\left(0.9 \mu \mathrm{mol} \mathrm{dm}{ }^{-3} \mathrm{day}^{-1}\right)$ and benthic processes $\left(1.6 \mu \mathrm{mol} \mathrm{dm}{ }^{-3} \mathrm{day}^{-1}\right)$ provides a potential for oxygen consumption of $2.5 \pm 1 \mu \mathrm{moldm}{ }^{-3} \mathrm{day}^{-1}$. This is described as "potential" as the value is likely an overestimate of oxygen consumption rates because it is unlikely that all of the sinking organic matter is remineralized pelagically. Much of this sinking organic matter is deposited before being remineralized, and therefore a portion of the DCM originating consumption $\left(0.9 \mu \mathrm{mol} \mathrm{dm}^{-3} \mathrm{day}^{-1}\right)$ is already accounted for in the benthic consumption $\left(1.6 \mu \mathrm{mol} \mathrm{dm}{ }^{-3} \mathrm{day}^{-1}\right)$.

Furthermore, no POC: chlorophyll $a$ ratio could be obtained from North Sea DCM phytoplankton communities in this region. It is likely that in reality the ratio is in fact lower than 50:1 as DCM phytoplankton communities are adapted to lower light conditions and contain greater concentrations of photopigments. If this were the case, it would only reduce the estimate of oxygen depletion potential from DCM export, reinforcing the implication that there are unresolved mechanisms contributing to the oxygen depletion. The 50:1 conversion ratio, as well as the amount of sinking organic matter, is likely to vary on a seasonal level through changes in community composition. Species composition and bacterial cycling within the DCM will also likely impact how labile sinking organic matter is. This estimate would benefit from further in situ studies of sinking rates and organic matter export from the DCM.

Our estimates can also be skewed due to aliasing from the glider's travel and advection. Distinguishing vertical processes such as injection events from horizontal advection or spatial aliasing from glider travel is critical when assessing oxygen dynamics. In this study, the temperature and salinity data allow different water masses to be distinguished; horizontal advection does occur throughout the bottom mixed layer. Such an event occurs at the end of the record and is excluded from our study.

Even by accounting for additional organic matter issuing from the DCM and SML (faecal pellets, lysed cells, zooplankton) and doubling the potential for oxygen consumption from the DCM, the sum of oxygen consumption potential from the DCM and the benthic compartment remain only marginally larger than the total net observed rate of dissolved oxygen consumption within the BML $\left(2.8 \mu \mathrm{mol} \mathrm{dm}{ }^{-3} \mathrm{day}^{-1}\right)$. This either implies oxygen resupply rates much lower than the $2 \mu \mathrm{mol} \mathrm{dm}^{-3}$ day $^{-1}$ identified in Fig. 8 or, more likely, the existence of an additional oxygen sink relevant to the time and location of the survey which has not been accounted for.

In the results of this study, observed net consumption is significantly greater than previously reported values in the literature. As previously stated, the observed rate of apparent oxygen utilization would lead to lower oxygen saturations than observed if maintained from the start of the stratified season until the glider deployment. The implication here is that the Seaglider surveyed the region during a short-lived or localized increase in apparent oxygen utilization.

If we look at the budget in a wider seasonal context and ignore the glider-observed net consumption rate $\left(2.8 \mu \mathrm{mol} \mathrm{dm}{ }^{-3} \mathrm{day}^{-1}\right)$, the estimates of oxygen supply and 
consumption derived above $\left(-2+2.5 \mu \mathrm{mol} \mathrm{dm}{ }^{-3} \mathrm{day}^{-1}\right)$ are in agreement with past studies of the North Sea where net seasonal consumption rates of $0.4 \mu \mathrm{mol} \mathrm{dm}{ }^{-3} \mathrm{day}^{-1}$ were observed (Greenwood et al., 2010). This also points to the unknown sink being either short-lived or very localized and explains why the observed net consumption rate does not correlate with previous studies.

\section{Potential dissolved oxygen sinks}

Several processes could account for this unidentified oxygen sink. Bacterial recycling within the BML is rarely accounted for and could contribute to this unaccounted for oxygen depletion. In addition, recent work has begun focusing more on the importance of resuspension events in seasonal oxygen depletion (Van der Molen et al., 2012; Couceiro et al., 2013; Thompson et al., 2011; Greenwood et al., 2010).

Background benthic DO consumption is limited by oxygen penetration depth and redox levels (Neubacher, 2009). When deep benthic organic matter is resuspended into an oxic water column, bioavailable surface area is greatly increased and oxygen is readily available leading to very rapid and short-lived oxidation of reductants such as nitrite, ammonium, and sulfide. Organic matter is likely also briefly degraded more rapidly when resuspended and more surface area is exposed to the oxic BML.

Three particular causes have been identified as providing enough turbulent energy to the seafloor to resuspend organic matter: tidal resuspension, large wind mixing events, and trawling (Van der Molen et al., 2012; Couceiro et al., 2013; Thompson et al., 2011; Jago et al., 2006, 2002; Van Raaphorst et al., 1998; Greenwood et al., 2010). Current speeds and storm events sufficient to cause resuspension have been recorded at both the OG and ND sites (de Jonge et al., 1996; Kröncke and Knust, 1995; Greenwood et al., 2010; Weston et al., 2008). The influence of trawling has only recently been investigated but has been shown to potentially lead to a small $(0.5 \%)$ decrease in BML DO (Van der Molen et al., 2012) in modelling studies. A strong resuspension event leading to an even greater decrease in DO was documented by Greenwood et al. (2010) at the Oyster Grounds.

In the 2011 survey data, glider observations of optical backscatter at $650 \mathrm{~nm}$ in the BML show the existence of resuspension events (Fig. 3e). Glider optical backscatter measurements showed fluctuations similar to that of chlorophyll $a$ concentrations with strong increases and rapid declines in BML backscatter. The distance from the seafloor at the deepest point of the dive prevents the glider from observing fluctuations of backscatter in the near-bottom fluff layer. Despite this, there is a clear gradient present with increasing backscatter nearer the seabed showing that bottom stress does resuspend some organic matter (Fig. 4e). The peaks in BML optical backscatter do not correlate with observed cross-pycnocline mixing (Fig. 8) but seem to occur on a diurnal cycle, about 4 to $6 \mathrm{~h}$ after daily peak wind speeds (Fig. 9).
Correctly understanding and quantifying resuspension becomes increasingly important when one considers temporary depocentres. These sites accumulate organic matter originating from much wider regions through slowing of currents. These sites have the capacity to rapidly sequester large amounts of organic matter, not only during peak production but also throughout the winter. This creates a reservoir of highly labile organic matter which, when resuspended, leads to very rapid consumption of DO. Depocentres are not exclusive to the North Sea; they are driven by local hydrography and topography, acting as hotspots of oxygen depletion in shelf sea environments around the world.

\section{Conclusions}

This study, through the use of an autonomous underwater ocean glider, has given new insights into the timescales of processes that regulate the supply and consumption of oxygen across thermoclines and into the BML. The average observed rate of oxygen consumption rate of $2.8 \pm 0.3 \mu \mathrm{mol} \mathrm{dm}^{-3} \mathrm{day}^{-1}$ is high; this would have resulted in the observed AOU of $76 \mu \mathrm{mol} \mathrm{dm}{ }^{-3}$ within only 1 month of the onset of stratification. The glider observations' high temporal and vertical resolution reveals the periods when resupply of oxygenated water occurs and enables these vertical processes to be distinguished from horizontal processes. Long-term trends in net oxygen consumption hide a more complex short-term variability reflecting variations in oxygen supply and consumption. During a period when the BML was isolated, the AOU was shown to increase significantly over a short 3-day period. The observed vertical mixing events have no apparent correlation with winds or tides, and remain a process to be further explored. Optical backscatter readings from the Seaglider in the BML showed varying suspended sediment, which generally increased near the bed and varied on diurnal timescales.

Greenwood et al. (2010) recorded average (since stratification) oxygen depletion rates in 2007 of $0.43 \mu \mathrm{mol} \mathrm{dm}^{-3}$ day $^{-1}$ at $\mathrm{ND}$ and $0.75 \mu \mathrm{mol} \mathrm{dm}^{-3} \mathrm{day}^{-1}$ at the OG. We observed export of organic matter from the DCM with the potential of consuming $0.9 \mu \mathrm{mol} \mathrm{dm}^{-3}$ day $^{-1}$, and the study by Neubacher (2009) found rates of $1.6 \mu \mathrm{mol} \mathrm{dm}^{-3} \mathrm{day}^{-1}$ for the sediment-water oxygen flux in incubation experiments. These rates highlight two particular aspects of the mechanisms governing seasonal oxygen depletion in the North Sea. The first is that consumption along the seafloor plays a predominant role in the consumption of BML oxygen. This supports the idea that depocentres, such as the OG, are particularly prone to seasonal oxygen depletion. Advected organic matter will add to the consumption budget, increasing the ratio of consumption to supply, whilst the reduced water flow that promotes this deposition also promotes stronger stratification. The second is that supply and consumption of organic matter are tightly coupled. Net oxygen depletion rates averaged over a 
season are 1 order of magnitude smaller than gross oxygen consumption and supply rates. A small shift in either gross DO consumption or supply would have a large impact on net oxygen consumption rates.

A recent study by Rovelli et al. (2015) observed much greater vertical mixing than is traditionally thought to be the case within the North Sea. Using a similar budgetbased approach, they identified consumption rates 5 times greater than those measured by Greenwood et al. (2010) $\left(\sim 2 \mu \mathrm{mol} \mathrm{dm}{ }^{-3}\right.$ day $\left.^{-1}\right)$. These rates, as well as high vertical mixing rates, are in agreement with our findings.

This study has shown the potential of new AUVs in regions such as the North Sea. This deployment was cut short and only $5 \%$ of battery capacity was utilized; a full duration glider deployment within the North Sea could last upwards of 2 months. Despite the deployment lasting only 3 days, the data revealed small-scale mixing mechanisms that would not be identifiable with traditional oceanographic methods. A longer glider deployment would provide more confidence in these estimates of rates and would reveal the temporal variability of biological processes across an entire season. A Seaglider performing repeat transects in and out of known depocentres could provide critical high-resolution observations of subsurface primary production and organic matter transport in regions of both low and high biomass accumulation.

A longer survey would also increase the likelihood of observing larger mixing events (i.e. storm events) and the impact these have on resuspension of organic matter and subsequent oxygen drawdown. High-resolution observations, such as those obtained by a glider, are critical to improving shelf sea ecosystem models. There remain limitations to such models; many processes are simplified and they do not resolve finer processes due to lack of understanding and observations, particularly feedback and subsurface processes. Van der Molen et al. (2012) highlight that, in the case of the North Sea, General Estuarine Transport Model-Biochemical Flux Model (GETM-BFM)'s representation of advection, particulate organic carbon transport, and remineralization requires further knowledge to adequately represent these carbon and oxygen dynamics. These are gaps that autonomous underwater vehicles, by providing season-long observations, could fill. These models could then, in turn, fill the gaps in glider observations to provide a comprehensive view of the processes occurring in these highly dynamic and heterogeneous environments. As it is now well established that many shelf seas undergo seasonal oxygen depletion (Diaz and Rosenberg, 2008), it is critical to increase the presence of persistent observation systems to improve models in order to provide useful policy advice about future developments.

Author contributions. B. Y. Queste, K. J. Heywood, and L. Fernand designed the study and provided the Seaglider. B. Y. Queste, L. Fernand, and A. J. Hind collected the data during the August 2011 sur- vey. B. Y. Queste corrected and interpreted the data and wrote the paper. All authors contributed significantly to the interpretation of the data and revisions of the manuscript.

Acknowledgements. This work and Bastien Queste were funded through a NERC Case studentship from the University of East Anglia and Cefas. The Cefas CASE contribution was made from Cefas Seedcorn funding. The research leading to these results has received funding from the European Union 7th Framework Programme (FP7 2007-2013) under grant agreement no. 284321 GROOM (www.groom-fp7.eu). The authors would like to thank the officers and crew of the RV Endeavour for their assistance in this work. Wind and atmospheric data were obtained from the European Centre for Medium-Range Weather Forecasts (ECMWF). Satellite chlorophyll data were obtained from the Ocean Biology Processing Group (OBPG) at the Goddard Space Flight Center. We thank the editor and reviewers for their valuable comments and suggestions which improved the manuscript.

Edited by: L. Stramma

\section{References}

Brown, J., Hill, A. E., Fernand, L., and Horsburgh, K. J.: Observations of a Seasonal Jet-like Circulation at the Central North Sea Cold Pool Margin, Estuar. Coast. Shelf S., 48, 343-355, doi:10.1006/ecss.1999.0426, 1999.

Burchard, H. and Rippeth, T. P.: Generation of Bulk Shear Spikes in Shallow Stratified Tidal Seas, J. Phys. Oceanogr., 39, 969-985, doi:10.1175/2008JPO4074.1, 2009.

Couceiro, F., Fones, G. R., Thompson, C. E. L., Statham, P. J., Sivyer, D. B., Parker, R., Kelly-Gerreyn, B. A., and Amos, C. L.: Impact of resuspension of cohesive sediments at the Oyster Grounds (North Sea) on nutrient exchange across the sediment-water interface, Biogeochemistry, 113, 37-52, doi:10.1007/s10533-012-9710-7, 2013.

de Jonge, V. N., Bakker, J. F., and Van Stralen, M.: Recent changes in the contributions of river Rhine and North Sea to the eutrophication of the western Dutch Wadden Sea, Netherlands Journal of Aquatic Ecology, 30, 27-39, doi:10.1007/BF02092145, 1996.

Diaz, R. J. and Rosenberg, R.: Spreading dead zones and consequences for marine ecosystems, Science, 321, 926-929, doi:10.1126/science.1156401, 2008.

Ducrotoy, J.-P., Elliott, M., and de Jonge, V. N.: The North Sea, Mar. Pollut. Bull., 41, 5-23, doi:10.1016/S0025-326X(00)00099-0, 2000.

Egbert, G. D., Erofeeva, S. Y., and Ray, R. D.: Assimilation of altimetry data for nonlinear shallow-water tides: Quarter-diurnal tides of the Northwest European Shelf, Cont. Shelf Res., 30, 668679, doi:10.1016/j.csr.2009.10.011, 2010.

Eriksen, C. C., Osse, T. J., Light, R. D., Wen, T., Lehman, T. W., Sabin, P. L., Ballard, J. W., and Chiodi, A. M.: Seaglider: a long-range autonomous underwater vehicle for oceanographic research, IEEE J. Oceanic Eng., 26, 424-436, doi:10.1109/48.972073, 2001. 
Fernand, L., Weston, K., Morris, T., Greenwood, N., Brown, J., and Jickells, T.: The contribution of the deep chlorophyll maximum to primary production in a seasonally stratified shelf sea, the North Sea, Biogeochemistry, 113, 153-166, doi:10.1007/s10533-013-9831-7, 2013.

GEBCO: The GEBCO_08 Grid, version 20100927, available at: http://www.gebco.net (last access: 19 February 2014), 2010.

Greenwood, N., Parker, E. R., Fernand, L., Sivyer, D. B., Weston, K., Painting, S. J., Kröger, S., Forster, R. M., Lees, H. E., Mills, D. K., and Laane, R. W. P. M.: Detection of low bottom water oxygen concentrations in the North Sea; implications for monitoring and assessment of ecosystem health, Biogeosciences, 7, 1357-1373, doi:10.5194/bg-7-1357-2010, 2010.

Hill, A., Brown, J., Fernand, L., Holt, J., Horsburgh, K., Proctor, R., Raine, R., and Turrell, W.: Thermohaline circulation of shallow tidal seas, Geophys. Res. Lett., 35, L11605, doi:10.1029/2008GL033459, 2008.

Jago, C., Jones, S., Latter, R., McCandliss, R., Hearn, M., and Howarth, M.: Resuspension of benthic fluff by tidal currents in deep stratified waters, northern North Sea, J. Sea Res., 48, 259 269, doi:10.1016/S1385-1101(02)00181-8, 2002.

Jago, C., Jones, S., Sykes, P., and Rippeth, T.: Temporal variation of suspended particulate matter and turbulence in a high energy, tide-stirred, coastal sea: Relative contributions of resuspension and disaggregation, Cont. Shelf Res., 26, 2019-2028, doi:10.1016/j.csr.2006.07.009, 2006.

Kröncke, I. and Knust, R.: The Dogger Bank: A special ecological region in the central North Sea, Helgoländer Meeresuntersuchun., 49, 335-353, doi:10.1007/BF02368361, 1995.

Lenhart, H. J., Radach, G., Backhaus, J. O., and Pohlmann, T.: Simulations of the north sea circulation, its variability, and its implementation as hydrodynamical forcing in ERSEM, Neth. J. Sea Res., 33, 271-299, doi:10.1016/0077-7579(95)90050-0, 1995.

Lenhart, H. J., Radach, G., and Ruardij, P.: The effects of river input on the ecosystem dynamics in the continental coastal zone of the North Sea using ERSEM, J. Sea Res., 38, 249-274, doi:10.1016/S1385-1101(97)00049-X, 1997.

Lenhart, H. J., Pätsch, J., Kühn, W., Moll, A., and Pohlmann, T.: Investigation on the trophic state of the North Sea for three years (1994-1996) simulated with the ecosystem model ERSEM - the role of a sharp NAOI decline, Biogeosciences Discuss., 1, 725754, doi:10.5194/bgd-1-725-2004, 2004.

Neubacher, E.: Oxygen and nitrogen cycling in sediments of the southern North Sea, Ph.D. thesis, Queen Mary, University of London, UK, 2009.

Otto, L., Zimmerman, J. T. F., Furnes, G. K., Mork, M., Saetre, R., and Becke, G.: Review of the physical oceanography of the North Sea, Netherlands J. Sea Res., 26, 161-238, doi:10.1016/00777579(90)90091-T, 1990.

Peña, M. A., Katsev, S., Oguz, T., and Gilbert, D.: Modeling dissolved oxygen dynamics and hypoxia, Biogeosciences, 7, 933957, doi:10.5194/bg-7-933-2010, 2010.

Queste, B. Y.: Hydrographic observations of oxygen and related physical variables in the North Sea and Western Ross Sea Polynya, Ph.D. thesis, University of East Anglia, Norwich, UK, 2014.

Queste, B. Y., Fernand, L., Jickells, T. D., and Heywood, K. J.: Spatial extent and historical context of North Sea oxy- gen depletion in August 2010, Biogeochemistry, 113, 53-68, doi:10.1007/s10533-012-9729-9, 2013.

Redfield, A. C.: On the proportions of organic derivatives in sea water and their relation to the composition of plankton, Tech. rep., doi:citeulike-article-id:11236440, 1934.

Rodwell, M., Rowell, D., and Folland, C.: Oceanic forcing of the wintertime North Atlantic Oscillation and European climate, Nature, 398, 320-323, http://www.nature.com/nature/journal/v398/ n6725/abs/398320a0.html, 1999.

Rovelli, L., Dengler, M., Schmidt, M., Sommer, S., Linke, P., and McGinnis, D. F.: Thermocline mixing and vertical oxygen fluxes in the stratified central North Sea, Biogeosciences Discuss., 12, 9905-9934, doi:10.5194/bgd-12-9905-2015, 2015.

Sathyendranath, S., Stuart, V., Nair, A., Oka, K., Nakane, T., Bouman, H., Forget, M. H., Maass, H., and Platt, T.: Carbonto-chlorophyll ratio and growth rate of phytoplankton in the sea, Mar. Ecol.-Prog. Ser., 383, 73-84, doi:10.3354/meps07998, 2009.

Sharples, J., Moore, M. C., Rippeth, T. P., Holligan, P. M., Hydes, D. J., Fisher, N. R., and Simpson, J. H.: Phytoplankton distribution and survival in the thermocline, Limnol. Oceanogr., 46, 486-496, doi:10.4319/1o.2001.46.3.0486, 2001.

Sharples, J., Ross, O., Scott, B., Greenstreet, S., and Fraser, H.: Inter-annual variability in the timing of stratification and the spring bloom in the North-western North Sea, Cont. Shelf Res. 26, 733-751, doi:10.1016/j.csr.2006.01.011, 2006.

Thomas, H., Bozec, Y., Elkalay, K., and de Baar, H. J. W.: Enhanced open ocean storage of $\mathrm{CO} 2$ from shelf sea pumping, Science, 304, 1005-1008, 2004.

Thomas, H., Bozec, Y., de Baar, H. J. W., Elkalay, K., Frankignoulle, M., Schiettecatte, L.-S., Kattner, G., and Borges, A. V.: The carbon budget of the North Sea, Biogeosciences, 2, 87-96, doi:10.5194/bg-2-87-2005, 2005.

Thompson, C., Couceiro, F., Fones, G., Helsby, R., Amos, C. L., Black, K., Parker, E., Greenwood, N., Statham, P., and Kelly-Gerreyn, B.: In situ flume measurements of resuspension in the North Sea, Estuar. Coast. Shelf S., 94, 77-88, doi:10.1016/j.ecss.2011.05.026, 2011.

Turrell, W., Henderson, E., Slesser, G., Payne, R., and Adams, R.: Seasonal changes in the circulation of the northern North Sea, Cont. Shelf Res., 12, 257-286, doi:10.1016/02784343(92)90032-F, 1992.

Van der Molen, J., Aldridge, J. N., Coughlan, C., Parker, E. R., Stephens, D., and Ruardij, P.: Modelling marine ecosystem response to climate change and trawling in the North Sea, Biogeochemistry, 113, 213-236, doi:10.1007/s10533-012-9763-7, 2012.

Van Haren, H., Maas, L., Zimmerman, J. T. F., Ridderinkhof, H., and Malschaert, H.: Strong inertial currents and marginal internal wave stability in the central North Sea, Geophys. Res. Lett., 26, 2993, doi:10.1029/1999GL002352, 1999.

Van Raaphorst, W., Malschaert, H., and Van Haren, H.: Tidal resuspension and deposition of particulate matter in the Oyster Grounds, North Sea, J. Mar. Res., 56, 257-291, doi:10.1357/002224098321836181, 1998.

Weston, K., Jickells, T. D., Fernand, L., and Parker, E. R.: Nitrogen cycling in the southern North Sea: consequences for total nitrogen transport, Estuar. Coast. Shelf S., 59, 559-573, doi:10.1016/j.ecss.2003.11.002, 2004. 
Weston, K., Fernand, L., Mills, D. K., Delahunty, R., and Brown, J.: Primary production in the deep chlorophyll maximum of the central North Sea, J. Plankton Res., 27, 909-922, doi:10.1093/plankt/fbi064, 2005.

Weston, K., Fernand, L., Nicholls, J., Marca-Bell, A., Mills, D. K., Sivyer, D. B., and Trimmer, M.: Sedimentary and water column processes in the Oyster Grounds: a potentially hypoxic region of the North Sea., Mar. Environ. Res., 65, 235-49, doi:10.1016/j.marenvres.2007.11.002, 2008.
Williams, C., Sharples, J., Green, M., Mahaffey, C., and Rippeth, T.: The maintenance of the subsurface chlorophyll maximum in the stratified western Irish Sea, Limnol. Oceanogr.: Fluids \& Environments, 3, 61-73, doi:10.1215/21573689-2285100, 2013a.

Williams, C., Sharples, J., Mahaffey, C., and Rippeth, T.: Winddriven nutrient pulses to the subsurface chlorophyll maximum in seasonally stratified shelf seas, Geophys. Res. Lett., 40, 54675472, doi:10.1002/2013GL058171, 2013b. 